\title{
Artes electrónicas en Argentina. En busca del eslabón perdido
}

\section{Adler, Jazmín [ver currículum del autor, docente de la Facultad de Diseño y Comunicación]}

\section{Resumen:}

La categoría de artes electrónicas comprende una pluralidad de prácticas ubicadas en la intersección del arte, la ciencia y la tecnología. Si bien diversos artistas argentinos contemporáneos se encuentran trabajando en este campo, las artes electrónicas parecen aún ser circunscritas a un universo aislado del resto de las manifestaciones artísticas actuales.

El presente artículo abre una serie de interrogantes ligados a las particularidades de las artes electrónicas latinoamericanas, en especial las argentinas, y a la posibilidad de trazar a través de ellas una aproximación a los componentes culturales locales. Seguidamente se desarrollan las estrategias implementadas por algunos artistas que han permitido encauzar la investigación artística sin repetir miméticamente imaginarios tecnológicos ajenos y heredados, ni adscribir a determinadas líneas discursivas como medios de legitimación de nuevas propuestas. El artículo concluye con el análisis de las instituciones abocadas a la difusión de las artes electrónicas en Argentina y otros países de América Latina. Asimismo, destaca la importancia de impulsar iniciativas que financien el aprendizaje, intercambio, producción, exhibición y reflexión sobre las artes electrónicas de nuestro país.

Palabras clave:

artes electrónicas - América Latina - arte argentino contemporáneo - low tech - soluciones creativas locales.
Cuadernos del Centro de Estudios de Diseño y Comunicación Nº 60

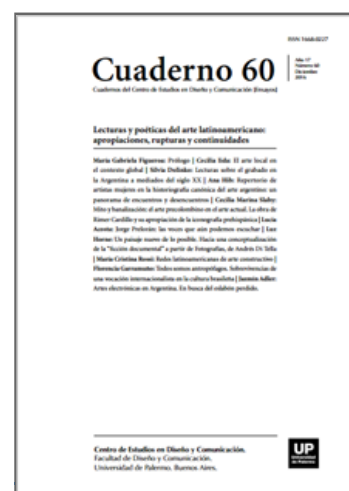

ISSN: 1668-0227

Lecturas y poéticas

del arte

latinoamericano:

apropiaciones,

rupturas y

continuidades

Año XVII, Diciembre 2016, Buenos Aires, Argentina | 176 páginas

descargar PDF

ver índice de la publicación

Ver todos los libros de la publicación

compartir en Facebook

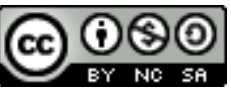

Esta obra está bajo una Licencia Creative

Commons Atribución-NoComercial-

Compartirlgual 4.0 Internacional 
*Licenciada en Artes (UBA). Becaria doctoral de CONICET. Investigadora de la Universidad Nacional de Tres de Febrero, y del Exploratorio Latinoamericano de Poéticas/Políticas Tecnológicas (Instituto Germani, Facultad de Cs. Sociales - UBA). Fue docente de la Facultad de Diseño y Comunicación de la Universidad de Palermo.

Viejas tensiones, nuevas propuestas

Cualquiera que sea el nombre con que llamemos a nuestras sociedades es evidente que la naturaleza específica de los procesos de aculturación nos convierte, irremediablemente, en receptores de culturas madres. Digo esto para aclarar que lo grave no es ser receptor sino confundir señal de ruta con lenguaje. (Marta Traba, 2005, p. 65) La pregunta por la identidad del arte latinoamericano constituyó uno de los tópicos que atravesaron la actividad plástica de los artistas de la región, al tiempo que ocupó un lugar central en los análisis críticos y debates historiográficos en torno a las propuestas estéticas del siglo XX. El universalismo constructivo, la vanguardia antropofágica y el muralismo mexicano, entre otros casos, procuraron elaborar un lenguaje artístico propio y colaborar así con la construcción identitaria de sus respectivos países, pero sin excluir el pasado local previo a la conquista. El retrato del indígena, la inclusión de símbolos prehispánicos, o la representación del paisaje nativo, todos ellos desprovistos del exotismo de la mirada europea, fueron combinados con los elementos proporcionados por los movimientos de vanguardia provenientes del Viejo Mundo. Las tensiones Norte-Sur que la Antropofagia sugería superar mediante el gesto ritual de asimilar la tradición occidental de acuerdo a las propias necesidades, o que Torres García apuntaba a revertir al dar vuelta el mapa del continente americano, todavía en cierto modo persisten, aunque por supuesto resinificadas en el marco de nuestra nueva era. El capitalismo multinacional, la globalización mediática, su propagación dispar en los distintos países del mundo, el multiculturalismo, y la transnacionalización del mundo, parecen haber actualizado la famosa dicotomía centro-periferia1. El creciente proceso de sociologización y antropologización del arte promovido por el multiculturalismo (Richard, 2007) apuntó a incluir y considerar a las periferias marginadas. Sin embargo, uno de los efectos directos de esta transformación fue la abolición de sus respectivas diferencias. El empleo de la noción de "arte latinoamericano" posiblemente conduzca a reproducir dicha lógica. Es por este motivo que Gerardo Mosquera sugiere hablar de "arte desde América Latina". Esta noción permite detectar la construcción de lo global desde la diferencia, y así evitar concebir a la región como un territorio homogéneo y totalizador o, por el contrario, completamente heterogéneo. Sin ir más lejos, muchos extranjeros llegan a la Argentina esperando arribar a un país con una fuerte impronta indígena, como sucede en Bolivia, Perú o México. La sorpresa es notoria cuando descubren una nación con evidentes características europeas en su población, arquitectura y gastronomía, resultantes de una historia que procuró literalmente eliminar su pasado aborigen. Si los cuestionamientos sobre las implicancias de ser latinoamericano se están transformando, evidentemente el arte latinoamericano, o el arte producido desde América Latina, también lo está haciendo. En los últimos años, a diferencia de la situación acontecida durante la primera mitad del siglo XX con los trabajos de las vanguardias latinoamericanas, los componentes culturales locales empezaron a manifestarse en los propios discursos de las obras: Los nuevos artistas parecen menos interesados en mostrar el pasaporte.

Los componentes culturales actúan más en el discurso de las obras que en su estricta visualidad, aún en los casos en que aquéllas se fundamentan en lo vernáculo (...). Este proceder implica una presencia del contexto y de la cultura entendidos en su sentido más amplio, e interiorizados en la manera misma de construir las obras y sus discursos. Pero también una praxis del propio arte, en cuanto arte, que establece constantes identificables, construyendo tipología cultural desde la manera de hacer el arte, y no acentuando los factores culturales introyectados en éste. Así, hay modos brasileños -y aún de Sâo Paulo, Río de Janeiro o Minas Gerais- 
identificables más porque refieren a maneras de hacer los textos que de proyectar los contextos. (Mosquera, 2000 , p. 7) Así, la tematización de ciertos elementos del folclore, la religión o el paisaje, todos ellos aspectos visuales que proyectan determinado contexto, ha tendido a ser sustituida por el predominio de rasgos y modos específicos de las prácticas artísticas de los distintos territorios.

Los debates acerca de los componentes culturales latinoamericanos expresados en las obras de arte contemporáneo son vastos y extendidos, al igual que lo son las frecuentes reflexiones relativas a las tensiones entre el Norte -central, hegemónico y poderoso en términos económicos y simbólicos-, y el Sur, periférico y subalterno. Sin embargo, es llamativa la escasez de investigaciones referidas a dichos temas particularmente en el campo de las artes electrónicas. Estas prácticas no responden a una estética unificada pero todas ellas se sitúan en la convergencia del arte, la ciencia y la tecnología, e incorporan los lenguajes electrónicos y/o digitales, tanto a nivel formal como conceptual, en las distintas instancias del proceso creativo: instalaciones interactivas, cuevas de realidad virtual, ambientaciones sonoras, esculturas robóticas, intervenciones digitales en el espacio público, videos, obras de net art, tecnopoesía y bioarte, entre otras. Aunque los antecedentes de las artes electrónicas se remontan a siglos atrás, es evidente la resistencia histórica a incluir las obras tecnológicas en el campo del arte contemporáneo (Shanken, 2013). Recurrentemente, los trabajos que analizan el panorama artístico actual excluyen capítulos, apartados y notas al pie dedicados a las obras electrónicas. En parte como consecuencia de estas constantes omisiones, el arte ligado a la ciencia y la tecnología ha sido relegado a un universo aislado del resto de las manifestaciones artísticas de nuestro tiempo.

Nos proponemos aquí favorecer a enmendar el descuido. Cabe inquirir cuáles son las características propias de las artes electrónicas de América Latina, qué diferencias podemos encontrar en las producciones de sus respectivos países, y de qué modo dichas prácticas entrevén aspectos culturales inherentes a estos territorios, ítem que permitiría una relectura de las viejas tensiones centro-periferia2. ¿Cómo se manifiesta esta disyuntiva en las obras de arte electrónico de la región? ¿Hasta qué punto podemos considerar que los componentes culturales locales también son configurados en este tipo de propuestas? ¿Qué dimensiones de las obras debemos concebir para divisar su impronta? Estrategias low tech. Tácticas vs. Exclusión

Una cuestión sugestiva desde la cual podemos ensayar posibles respuestas remite a las posibilidades de acceso a la tecnología en América Latina, determinadas por las políticas económicas, culturales, estatales y/o empresariales de cada uno de los territorios. No podemos obviar el hecho de que las obras tecnológicas de la región son producidas en un escenario específico, históricamente caracterizado por la dispar distribución de la tecnología en los distintos países latinoamericanos, tanto con respecto a las naciones centrales, como inclusive entre los distintos sectores de su misma población. Por otra parte, el desarrollo de las artes tecnológicas en los distintos territorios latinoamericanos exhibe notables diferencias.

El mayor número de obras tecnológicas se concentran en una cantidad acotada de países, como Brasil, México o incluso Argentina, mientras que en otras zonas como Guatemala, Nicaragua, Honduras o El Salvador, la producción es todavía relativamente escasa (Mariátegui \& Villacorta, 2004). En este sentido, Andrea Giunta y Néstor García Canclini ampliaron el concepto de extranjería, preguntándose por la condición de ser extranjero en la cultura3. Precisamente, entre los nuevos significados que los autores evocan se encuentra la definición del extranjero como aquel que ha quedado excluido de las nuevas tecnologías. 
Frente a circunstancias afines a aquellas, algunos artistas de nuestro país han decidido adoptar una estética low-tech, a través de la utilización de componentes de fácil acceso por sus costos poco elevados. El empleo de la baja tecnología constituye en algunas obras una estrategia implementada de modo intencional para referir al entorno en el cual los artistas residen y producen. No se trataría de recurrir a esta alternativa como resignación frente a la imposibilidad de obtener otros recursos, sino una respuesta original, crítica y consciente (Alonso, 2002). La obra de Leo Núñez sería un buen ejemplo de esta línea. Núñez considera que América Latina se encuentra en desventaja con respecto a la distribución de la tecnología a nivel mundial, y declara que su producción representa su contexto4. A través del empleo de tecnología low-tech, así como mediante la exploración de las relaciones posibles entre el hombre y la máquina, sus trabajos suelen hacer uso de componentes tecnológicos accesibles. En Tecnología led (2010)5, por ejemplo, el artista tematiza la desigual distribución tecnológica en el mundo mediante una instalación interactiva conformada por una pantalla semi mecánica compuesta por dispositivos sencillos como leds y relays.

Tanto la iluminación producida por los primeros, como los chasquidos generados por los segundos, varían de acuerdo al desplazamiento de los visitantes. Tecnología led pone de manifiesto una oposición entre la baja y la alta tecnología de dos modos simultáneos: por un lado, contrasta el monitor low-tech con el software sofisticado creado para capturar la imagen del público. Por otro lado, la obra ubica a los usuarios entre unas tecnologías y otras, debido a que la pantalla con la que interactúan los visitantes se monta justo enfrente del sistema de computación.

La baja tecnología también integra la obra de artistas que eligen trabajar con materiales caducos. Marco Bellonzi y David Casacuberta (2007), integrantes del grupo de investigación Imarte, dependiente de la Facultad de Bellas Artes de la Universidad de Barcelona, consideran que el arte low-tech constituye una posición ética, estética e ideológica, ligada a la reutilización de dispositivos obsoletos y opuesta al arte high-tech, abocado a las tecnologías emergentes, sofisticadas y costosas. En esta vertiente ubicamos a ciertos artistas que recuperan televisores antiguos, computadoras desarmadas, videocaseteras, disquetes, celulares, juguetes de otras épocas, etcétera. En todos estos casos, lo low no implica únicamente la decisión de trabajar con materiales asequibles en el sentido económico, sino reciclar tecnologías caducas que ya han sido suplantadas por otras más novedosas. Esto supone la apropiación y reinvención de recursos tecnológicos preexistentes en operaciones asociadas al DIY (do it yourself), hackerismo, circuit bending y la cultura libre6. Son asimismo estrategias que construyen nuevos significados a partir de tecnologías provenientes de contextos disímiles. Aquí podemos ubicar a las obras de Jorge Crowe creadas a partir de la transformación de todo tipo de objetos encontrados; Leonello Zambón, quien diseña instalaciones, videos e intervenciones urbanas siempre reutilizando tecnologías que han sido descartadas; Constanza Piña cuya producción se centra en la realización de circuitos blandos7 y wearables (tecnologías "vestibles") con materiales caseros y reciclados; y también al sello discográfico y colectivo artístico BlipBlop, que produce música electrónica con viejas computadoras y consolas de videojuegos. En particular, Crowe declara que su trabajo es "orgullosamente tercermundista" 8 : con un pie en la high tech y el otro en las ferias y los mercados de pulgas donde descubre los objetos que más tarde interviene, el artista altera el orden jerárquico de los valores de las cosas que selecciona y modifica.

\section{Soluciones creativas locales}

"Sobre el plano de composición no hay ni pasado ni porvenir porque, finalmente, no hay historia, hay sólo geografía". (Deleuze, 2005, p. 314) Si analizamos la producción artística tecnológica argentina producida en los 
últimos doce años, notamos que han también existido propuestas que resultaron de las singularidades del contexto latinoamericano, pero que no optaron por evidenciar la escasez de ciertos recursos tecnológicos en nuestra región, ni tampoco su caducidad. Nos referimos a determinadas obras que, en lugar de situar su discurso material, estético y político en las antípodas de las tecnologías de punta propias de los países centrales, nacieron como soluciones creativas a limitaciones y problemáticas locales específicas. Dichas soluciones surgirían de dos situaciones diferenciadas no excluyentes: por un lado, de la obligación de adaptar la obra, durante el curso de su realización, a las tecnologías disponibles en el mercado local. Por otro lado, geminarían de la necesidad de concebir la pieza desde los inicios del proyecto previendo que ciertos dispositivos tecnológicos no se encuentran al alcance en el contexto de trabajo. De allí, la imposibilidad de pensar una independencia entre las prácticas artísticas que involucran a la tecnología y su respectivo carácter político. Dice Claudia Kozak: (...) como el fenómeno técnico/tecnológico de cada época está atado a una sociedad determinada, esto implica cierta historicidad y construcción social hegemónica del sentido de lo tecnológico. Se trata así de un fenómeno político que no puede ser abordado desde una supuesto neutralidad.

En tanto las poéticas tecnológicas asumen el fenómeno técnico que les es contemporáneo son también políticas. (Kozak, 2012, pp. 182-183) Una solución creativa local interesante es aquella implementada por Mariano Sardón en el desarrollo de Libros de Arena (2003-2004)9, con la colaboración técnica de Laurence Bender. La obra consiste en una instalación interactiva integrada por dos cubos de vidrio colmados de arena, material que el usuario es invitado a manipular. A medida que una cámara captura los movimientos de las manos de quienes interactúan con la pieza, estos datos son asociados a hipertextos extraídos de la Web que contienen textos de Jorge Luis Borges. El resultado es la proyección de los textos sobre la arena, imágenes relacionadas a los sucesivos movimientos de las manos de los usuarios. Sardón regresó a la Argentina en el contexto posterior a la crisis del 2001, luego de haber residido en la ciudad de Los Ángeles, trabajando en la Universidad de California. En aquel entonces en nuestro país resultaba imposible acceder a las tecnologías Macintosh que el artista había utilizado en el extranjero. Las tecnologías de captura y análisis de imagen en tiempo real, logradas mediante la conexión de una cámara de video a una computadora, y el procesamiento de la imagen en el mismo momento, funcionaban únicamente con determinados programas que no estaban desarrollados para entornos de PC. Para suplir esta carencia, Sardón desarrolló junto a Laurence Bender, físico y realizador de cine, un software que pudiera funcionar con la tecnología disponible. Este proceso de investigación resultó una experiencia sumamente enriquecedora, produciendo como resultado la elaboración de contenidos de la carrera de Artes Electrónicas de la Universidad Nacional Tres de Febrero, institución sobre la que volveremos más adelante. Así, de la escasez de recursos surgió tanto una solución creativa alternativa, como un fructífero proceso pedagógico.

Un ejemplo de la segunda situación que identificamos más arriba -la necesidad de concebir la obra desde sus comienzos considerando que no se dispondrán determinados recursos-, lo encontramos en la obra de Diego Alberti, artista sonoro y audiovisual, quien sostiene que antes de empezar a trabajar en sus proyectos piensa qué podrá en realidad efectuar de todo aquello que idealmente haría. El artista considera que si se cuenta con los recursos financieros necesarios, prácticamente todo es posible. Su obra titulada Cajas (2002-2011)10, surgida de la intención de filmar un cortometraje, nos acerca a la situación descrita. Una vez creado el guión, Alberti salió con su equipo a producir las escenas. Como las características del material obtenido no le permitían su edición en el sentido narrativo tradicional de un corto, pero sí admitían la producción de diferentes escenas bien identificadas, el artista pensó en aprovechar la posibilidad ofrecida por el DVD de organizar las imágenes 
en distintos capítulos. Sin embargo, ocurrió que trabajando en PC no lograba el tipo de edición que buscaba. Fue recién en el año 2007 cuando pudo crear un DVD doble multiángulo haciendo uso de la computadora Mac que había sido adquirida por el estudio en el cual trabajaba. La función multiángulo permite saltar a diferentes capas del video pero sin interrumpir el sonido. Los primeros experimentos desarrollados por Alberti con este recurso consistieron en pixelar las imágenes originales, descomponiéndolas en distintos recuadros de colores. Luego decidió darle volumen a los píxeles, para lo cual creó un software que convirtió los recuadros en cubos o cajas que se desplazan en un espacio tridimensional, controlado por el artista a través de un joystick. Finalmente obtuvo dos DVD, uno referido a la historia de "él" y otro a la de "ella". Lo único que el público puede decidir es si desea ver la capa original del video, la capa de las imágenes pixeladas, o la capa de los cubos. Por lo demás, procuró restringir las funciones del control remoto de modo que, al insertar el disco, la obra se reproduce automáticamente, sin que el espectador pueda intervenir en el recorrido aleatorio del video por las distintas escenas que lo integran.

En 2010 ideó una videoinstalación que proyecta las tres imágenes en simultáneo. Al igual que la creación del DVD que solo fue logrado al tener acceso al entorno Mac, la videoinstalación pudo materializarse cuando Alberti contó con una computadora que corriera las tres capas de video, con las tres salidas de video y los tres monitores análogos.

El contexto desde el cual la obra es producida configura ciertas perspectivas, decisiones y procesos creativos. La noción de contexto puede resultar taxativa y limitante al referir a un conjunto cerrado de circunstancias preexistentes. Aquí no es entendida en términos de lo vernáculo, sino que alude a las posibilidades específicas que el entorno propicia, condiciona o restringe, pero que son construidas en la propia acción: Nunca un plano de composición o de consistencia preexiste, nunca ocurre sin que un grupo de individuos o de individuaciones lo tracen efectivamente.

Es un plano de inmanencia absoluto, pero esta inmanencia es precisamente inmanente a los grados de velocidad y lentitud, a los movimientos y reposos, a los poderes de ser afectado que lo construyen poco a poco (...).

Es el otro polo del plano el que podría presentarse como preexistente, con las personas o los grupos evolucionando sobre él. (Deleuze, 2005, p. 313) Al relatar la experiencia de su residencia en Estados Unidos, Nicolás Varchausky11, artista sonoro, compositor y performer, destaca la dificultad que inicialmente experimentó para idear un proyecto artístico que fuera diseñado sin concebir potenciales restricciones presupuestarias o tecnológicas. No se trata en absoluto de idealizar otros contextos, ni de ignorar las complejidades inherentes al sistema. Nos interesa en cambio comprender de qué modos las situaciones de cada entorno repercuten en la construcción de ciertas experiencias y prácticas de pensamiento, concibiéndolas a su vez -nuevamente recuperando las ideas deleuzianas- como velocidades, intensidades y lentitudes que construyen al plano de inmanencia como un espacio progresivo, fragmento por fragmento (Deleuze, 2005, p. 216). Una hipótesis que en algunas ocasiones se ha propuesto, y que en otra oportunidad analizaremos con mayor profundidad, es que en nuestro ámbito no se producen demasiadas obras que involucran tecnologías sofisticadas de altos costos en parte porque no es frecuente que los artistas consideren dicha posibilidad. Entre otras causas, esta situación resulta de la exigencia de que, para procurar los recursos requeridos, el artista debe desempeñar paralelamente el rol de gestor, tarea que frecuentemente excede sus tiempos y competencias. 
Como contracara de esos casos, Joaquín Fargas, pionero en el campo del bioarte en Argentina, asegura que jamás considera que no contará con los recursos que sus proyectos precisan. Las obras de Fargas efectivamente comienzan a ser formuladas imaginando qué características tendrían si el artista obtuviera el presupuesto suficiente y los dispositivos necesarios para concretar sus planes. Más tarde la realidad se ocupa de ir reduciendo las ideas a formatos más pequeños. Sin embargo, la solución desarrollada por el artista fue crear obras escalables, es decir, piezas que puedan ser plasmadas en distintos tamaños, aunque las múltiples versiones no difieren a nivel conceptual. Este es el caso de Sunflower, Centinela del Cambio Climático (2007)12, una flor metálica de seis metros de diámetro que sigue el movimiento del sol, realizada para la ciudad de Ushuaia. Sus pétalos se abren al amanecer, y están integrados por paneles solares que producen la energía necesaria para que la flor monitoree las condiciones ambientales del entorno durante el día y se ilumine por la noche. Sunflower controla la polución de aire, las temperaturas, la radiación UV y toma fotografías del sol, del paisaje y de la propia flor. Además de esta versión de gran tamaño, existe otra de dos metros de diámetro, y el artista está trabajando en prototipos aún más pequeños. Lo mismo sucede con sus biosferas, esculturasinstalaciones conformadas por esferas de policarbonato herméticamente selladas. Cada una de las esferas contiene un pequeño ecosistema, con tres cuartas partes de aire y una cuarta parte de agua, vegetación y microorganismos. También las biosferas pueden presentarse en distintas escalas, desde dos metros hasta diez centímetros de diámetro.

Aparentemente la carencia tecnológica que en el pasado constituyó un problema significativo, hoy en día ya no representaría un impedimento clave. Sería tan solo un obstáculo que, aunque dificulta el proceso creativo, podría ser en parte superado mediante la obtención de los recursos económicos necesarios. Sin embargo, sería ingenuo relegar la solución del problema a la cuestión financiera, descuidando el carácter sustancial desempeñado por aspectos de gestión e infraestructura. Al referirse al escenario argentino, Diego Hurtado sostiene: (...) Hoy el país tiene la capacidad de fabricar satélites, pero debe pagar muchos millones de dólares para ponerlos en órbita. Estas historias muestran que no importa cuánto capital se invierta, ni la capacidad de los científicos e ingenieros involucrados, ni el grado de avance alcanzado, ni los metros cúbicos de instalaciones, la volatilidad de los proyectos de desarrollo de tecnologías complejas en los países periféricos depende de manera vital de la capacidad de gestión política y diplomática. (Hurtado, 2010, pp. 232-233) La cuestión central no es entonces qué tecnologías se utilizan, sino cómo se las emplea. Los dispositivos tecnológicos no deben necesariamente determinar las ideas plasmadas en las obras, o ser elegidos en pos de alcanzar determinados resultados preconcebidos. Aquellos no tienen por qué ser el aspecto en torno al cual se diseña la obra, del mismo modo que una pieza escultórica no está constreñida a cavilar sobre las propiedades del mármol, la madera, el cincel, u otros materiales y herramientas implicados. Hace doce años, Claudia Gianetti detectaba que los efectos de seducción producidos por las tecnologías repercutían sobre las nuevas generaciones de artistas: Las tecnologías por si mismas no producen nada creativo. La creatividad está en la cabeza de aquellos que están detrás de las máquinas (...) Entre los artistas jóvenes, o las personas que se están formando en este ámbito, hay una fascinación tan grande por la tecnología, que la tendencia a veces es quedarse en la herramienta. La herramienta como tal tiene que ser siempre un elemento secundario. (Gianetti, 2002, p. 2) El desarrollo de soluciones creativas y la incorporación de tecnologías low tech como estrategia reflexiva encarnan dos tipos de tácticas que han sido implementadas en Argentina para encauzar la investigación artística sin colocar al discurso de la obra al servicio de innovaciones propias de otros contextos, o de los dispositivos involucrados. Estas observaciones de ningún modo presuponen una postura conservadora, reacia a la incorporación de dispositivos, ideas y procedimientos exógenos que se consideren ricos para inspirar 
a nuestros propios espacios de reflexión y producción. Sin embargo, señalamos la significación de evitar la repetición mimética de imaginarios ajenos y heredados, o la adscripción a determinadas líneas discursivas como medios de legitimación de nuevas propuestas locales.

\section{Peripecias de una odisea latinoamericana}

Llegados a este punto, consideramos que para fundar un campo de las artes electrónicas propio debemos formular preguntas pertinentes, genuinas y afines a los contextos geográficos y temporales de producción artística, científica y tecnológica. Un paso indispensable para ello es el impulso de la creación de instituciones que financien el aprendizaje, intercambio, producción, exhibición y, especialmente, la reflexión sobre las artes electrónicas locales. El Espacio Fundación Telefónica constituye uno de los pocos sitios que durante los últimos diez años se ha dedicado de forma exclusiva a promover el campo de las artes tecnológicas en nuestro país, a través de diversas exposiciones nacionales e internacionales, entrevistas a artistas y teóricos, simposios, coloquios, mesas redondas y publicaciones especializadas. Junto al Museo de Arte Moderno de Buenos Aires, lanzó en 2002 el reconocido premio MAMBA - Fundación Telefónica. Arte y Nuevas Tecnologías, con el objetivo de fomentar la producción de obras ligadas a la ciencia y la tecnología, entre ellas videos, instalaciones interactivas y piezas robóticas. El Espacio Fundación Telefónica es también sede del Taller Interactivos, un reconocido programa de especialización en estética, curaduría y montaje de obras tecnológicas, coordinado por Rodrigo Alonso y Mariano Sardón, que ha formado a muchos de los artistas argentinos que actualmente trabajan en la intersección del arte, la ciencia y la tecnología. En esta misma línea, cabe destacar al laboratorio de producción del MediaLab del Centro Cultural de España en Buenos Aires, que ha sustentado proyectos artísticos y tecnológicos, brindando el apoyo económico, el equipamiento y el asesoramiento técnico y estético para poder producirlos. Particularmente en el ámbito de las artes audiovisuales, Jorge La Ferla y Mariela Cantú (2008) han subrayado el carácter pionero del Instituto de Cooperación Iberoamericana por su difusión del videoarte en Argentina, así como la Fundación Antorchas, el Centro Cultural Ricardo Rojas, la Fundación TYPA, el Fondo Nacional de las Artes, el Instituto Goethe, el Servicio Cultural de la Embajada de Francia, la Alianza Francesa, el Museo de Arte Moderno y el Museo de Arte Latinoamericano de Buenos Aires. Podríamos a esta lista sumar algunas exposiciones realizadas por la Fundación Proa, como Harun Farocki; Artist's Film International; Mariano Sardón- Mariano Sigman. 200 miradas recorriendo sus rostros; o Mariela Yeregui - GAE.

Octópodos sísficos. Vale asimismo mencionar la propuesta de FASE, un encuentro de arte y tecnología organizado anualmente desde 2009. Acogido por el Centro Cultural Recoleta, en sus distintas ediciones el evento ha exhibido obras de distintos artistas argentinos y extranjeros, y trabajos de alumnos de diferentes carreras vinculadas a las artes tecnológicas, además de incluir charlas, talleres, proyecciones y performances en su programación.

Entre los aún escasos estudios universitarios que proporcionan una formación en arte y tecnología, recalcamos la misión precursora de la Universidad Nacional de Tres de Febrero (UNTREF), institución que creó la Licenciatura en Artes Electrónicas en 2000 y, nueve años más tarde, la Maestría en Tecnología y Estética de las Artes Electrónicas13. El Centro de Experimentación e Investigación en Artes Electrónicas de dicho establecimiento y la Universidad Tecnológica Nacional (UTN) han impulsado el Encuentro de Cooperación e Intercambio, una jornada que invita a que investigadores y artistas compartan los avances de sus proyectos. Otra institución relevante para la enseñanza e investigación en este campo es la Universidad Maimónides, cuyo 
Laboratorio Argentino de Bioarte promueve el desarrollo de obras que exploran la relación del arte con las prácticas biotecnológicas.

UTN, UNTREF y la Universidad Maimónides, junto a la Fundación para el Desarrollo del Conocimiento (Fundesco) y el apoyo de Fundación Itaú, han lanzado el Premio ArCITec, que otorga premios y menciones a artistas y científicos abocados a la creación de obras tecnológicas, y al desarrollo de tecnologías aplicadas al arte.

Más allá de estas iniciativas, exceptuando el caso de la Fundación Telefónica, todavía se encuentra postergada la creación de un museo o centro cultural que se dedique de manera íntegra y sistemática a la investigación y difusión de las prácticas artísticas tecnológicas argentinas, y que al mismo tiempo funcione como punto de encuentro entre artistas y teóricos del país. Este punto es fundamental para estimular la intersección entre la labor académica y el trabajo artístico tecnológico, principalmente porque en nuestro medio sus respectivas actividades parecen discurrir por caminos paralelos. Es asimismo evidente la exigua comunicación entre gran parte de las pocas instituciones anteriormente mencionadas.

No podemos dejar de destacar además el hecho de que todos los espacios expositivos y educativos a los cuales nos hemos referido se encuentran aglutinados en Buenos Aires.

Esta circunstancia hace eco de la evidente disparidad entre las posibilidades existentes en la capital con respecto al interior del país, exceptuando en cierta medida los casos de otras ciudades cabeceras como La Plata, Córdoba y Rosario, que también cuentan con algunas instituciones interesadas en promover el desarrollo de las artes electrónicas locales14. Así, la mayor parte de las provincias argentinas son convertidas en territorios periféricos en relación a la metrópolis porteña, aspecto que demuestra el actual carácter móvil, relativo y lábil de las locaciones designadas como centro y periferia15.

El contrapunto de este escenario es el caso brasileño; Brasil ha logrado gestionar significativas políticas gubernamentales y proyectos corporativos consumados en la progresiva creación de diversos museos, centros culturales, exposiciones, premios, festivales, programas universitarios y residencias reconocidos a nivel mundial. Algunas de las iniciativas que señalan la riqueza del ámbito del arte y la tecnología brasileños son el Centro Cultural Banco do Brasil, el Instituto Itaú Cultural, la Pinacoteca de San Pablo, el Museo de Imagen y Sonido de la misma ciudad, la Fundación Oi Futuro, con sedes en Río de Janeiro y Belo Horizonte, el Instituto Sergio Motta, el premio homónimo, otorgado por la institución para fomentar las artes electrónicas brasileñas, la Muestra 3M de Arte Digital, los Festivales Videobrasil (luego devenido en el Festival Internacional de Arte Electrónico), FILE - Festival Internacional de Lenguaje Electrónico, Vivo arte.mov - Arte en Medios Móviles, el laboratorio medial NAT (Núcleo Arte y Tecnología) de la Escuela de Artes Visuales de Parque Lage en Río de Janeiro, y las carreras orientadas a las artes mediales del Departamento de Artes Visuales de la Universidad de San Pablo. Otros emprendimientos latinoamericanos meritorios que han contribuido con el estudio, la reflexión y la subvención de las artes tecnológicas de cada uno de sus países son el Centro Multimedia, ubicado en México D.F. y dependiente del Consejo Nacional para la Cultura y las Artes, el Laboratorio de Arte Alameda, fundado por el mismo Consejo mediante el Instituto Nacional de Bellas Artes de México, el Centro Ático de la Universidad Javeriana de Bogotá, y la organización Alta Tecnología Andina de Lima, financiada por donaciones de distintas organizaciones internacionales, como la Fundación Daniel Langlois para el Arte, la Ciencia y la Tecnología. 
El campo de las artes electrónicas argentinas aún tiene un largo camino por recorrer. Si evaluamos los modelos latinoamericanos que hemos citado, constatamos que los respaldos de políticas estatales, determinadas corporaciones, y ciertas organizaciones sin fines de lucro nacionales e internacionales, resultan imprescindibles desde el punto de vista institucional y económico para estar en condiciones de emprender este trayecto. Será ciertamente un extenso viaje colmado de circunstancias prósperas y adversas, pero sin duda un recorrido encauzado por preguntas pertinentes para nuestros tiempos y geografías.

\section{Notas}

1. Acuñamos aquí las categorías de centro y periferia sin descuidar los cuestionamientos que han sido propuestos para revisar estos términos. Recientemente Andrea Giunta proclamó la invalidez del esquema de centros y periferias para abordar el arte contemporáneo y lo sustituyó por el concepto de "vanguardias simultáneas", noción que permite considerar las situaciones específicas activadas por obras insertas en la lógica global (Giunta, 2014). Los debates trazados en torno a estas categorías aún se encuentran abiertos. Hacia el final del artículo retomamos este punto.

2. Al analizar la relación entre los comportamientos etnocéntricos y las territorialidades periféricas, Mariela Yeregui plantea que las territorialidades son periféricas desde la perspectiva del agente que articula la perspectiva etnocéntrica (Yeregui, 2013).

3. La condición de ser extranjero en la cultura y la tecnología fue el tema central del proyecto de investigación "Extranjeros en la Tecnología y la Cultura", coordinado por Néstor García Canclini durante los años 2007 y 2008. El proyecto comprendió una serie de encuentros con artistas antropólogos, historiadores, sociólogos y otros especialistas, quienes fueron invitados a reflexionar sobre los nuevos significados e implicancias del ser extranjero en nuestros días. La investigación desembocó en 2009 en la exposición Extranjerías, co-curada por García Canclini y Andrea Giunta. La exposición tuvo lugar en el Espacio Fundación Telefónica de Buenos Aires entre octubre y diciembre de 2009, y estuvo integrada por obras de Carlos Amorales (México), Pat Badani (Canadá), Martín Bonadeo (Argentina), Mariana Castillo Deball (México), Roberto Jacoby (Argentina), Jorge Macchi (Argentina), Liliana Porter (Argentina), Mariano Sardón (Argentina), Leonardo Solaas (Argentina) y Tamara Stuby (Argentina).

4. Entrevista a Leo Núñez. Disponible en: http://www.unr.edu.ar/noticia/5189/arte-y-tecnologia-con-leo-nunez (consultado el 15 de mayo de 2014).

5. Documentación de la obra disponible en: http://www.leonunez.com.ar/tecnologia_led.html (consultado el 16 de mayo de 2014).

6. La cultura libre fomenta la circulación irrestricta de bienes culturales. En el campo de las poéticas electrodigitales este concepto está asociado al de software libre, un modo de creación y difusión de programas informáticos que otorgan la libertad de ejecutarlo para cualquier propósito, modificarlo accediendo al código fuente, y distribuir copias de cualquiera de sus versiones.

7. Los circuitos blandos (soft circuits) son aquellos circuitos electrónicos que se realizan en telas y otros materiales conductores. Se denominan "blandos" porque pueden doblarse, retorcerse y adaptarse a cualquier 
prenda o accesorio sin quebrarse.

8. Esta idea fue expresada por Crowe en una entrevista realizada por el grupo de investigación "Metodologías de la investigación basada en la práctica artística" (UNTREF - dir: Mariela Yeregui), del cual formamos parte. Véase: Yeregui, M. (comp.). Prácticas de pensamiento en las artes electrónicas (y viceversa). Buenos Aires: Autores de Argentina. Diego Alberti, Nicolás Varchausky y Joaquín Fargas, a quienes mencionamos más adelante, fueron también entrevistados por el mismo grupo.

9. Documentación de la obra disponible en: http://www.marianosardon.com.ar/mamba/libros_arena_esp.htm (consultado el 16 de mayo de 2014).

10. La documentación de la obra está disponible en: http://olaconmuchospeces.com.ar/archives /52\#more-52 (consultado el 17 de mayo de 2014).

11. El artista residió entre 2007 y 2011 en Seattle, Estados Unidos, con motivo de la realización de sus estudios doctorales en DXARTS (Centro de Arte Digital y Medios Experimentales de la Universidad de Washington).

12. Documentación de la obra disponible en: http://www.joaquinfargas.com.ar/sunflower/index_es.htm (consultado el 19 de mayo de 2014).

13. Los directores de la Licenciatura en Artes Electrónicas y la Maestría en Tecnología y Estética de las Artes Electrónicas son Mariano Sardón y Mariela Yeregui respectivamente.

14. Entre ellas, la Facultad de Bellas Artes de la Universidad Nacional de La Plata, donde se dicta la carrera de Diseño Multimedial, la Universidad Nacional de Córdoba (hacia el 2006 creó una especialización en artes mediales que actualmente por motivos burocráticos se encuentra en suspenso), el Centro Cultural España Córdoba, iniciativas de la Universidad Nacional de Rosario, el Centro Cultural Parque de España de la misma ciudad, y espacio- LAB, un programa en arte, ciencia y tecnología del Complejo Astronómico de Rosario.

15. La ruptura del esquema clásico centro-periferia provocado por el proceso de transnacionalización de la economía y la cultura, ha ocupado un lugar destacado en las investigaciones y debates de los últimos años. Para ampliar este punto, véase: Castro Gómez, S. \& Mendieta, E. (eds.) (1998). Introducción: La translocación discursiva de Latinoamérica en tiempos de la globalización. En Teorías sin disciplina (latinoamericanismo, poscolonialidad y globalización en debate). México: Miguel Ángel Porrúa.

\section{Bibliografía}

Alonso, R. (2002). Elogio de la Low Tech. En: Burbano, A. \& Barragán, H. (eds.). Hipercubo/ ok. Arte, Ciencia y Tecnología en Contextos Próximos. Bogotá: Universidad de los Andes; Goethe Institut.

Cantú, M. \& La Ferla, J. (2008). En Aramburu, N. (ed). Un lugar bajo el sol. Los espacios para las prácticas creativas actuales / Revisión y análisis. Buenos Aires: CCEBA AECID.

Castro Gómez, S. \& Mendieta, E. (eds.). (1998). Introducción: La translocación discursiva de Latinoamérica en tiempos de la globalización. En Teorías sin disciplina (latinoamericanismo, poscolonialidad y globalización en 
debate). México: Miguel Ángel Porrúa.

Deleuze, G. (2005). Derrames entre el capitalismo y la esquizofrenia. Buenos Aires: Cactus. García Canclini, N (2009). Extranjeros en la tecnología y en la cultura. Buenos Aires: Ariel.

Giunta, A. (2014). ¿Cuándo empieza el arte contemporáneo?. Buenos Aires: Fundación arteBA.

Hurtado, D. (2010). La ciencia argentina. Un proyecto inconcluso: 1930-2000. Buenos Aires: Edhasa.

Kozak, C. (ed.) (2012): Tecnopoéticas Argentinas. Archivo blando de arte y tecnología. Buenos Aires: Caja negra.

Latina. Arte en América Latina: tránsitos globales. En León, R. (ed.) (2002). Arte en América Latina y cultura global. Santiago de Chile: Facultad de Artes de la Universidad de Chile.

Mosquera, E. (2000). Good-Bye identidad, welcome diferencia: del arte latinoamericano al arte desde América.

Traba, M. (2005). Dos décadas vulnerables en las artes plásticas latinoamericanas. 1950-1970. Buenos Aires: Siglo XXI.

Richard, N. (2007). Fracturas de la memoria: Arte y pensamiento crítico. Buenos Aires: Siglo XXI.

Shanken, E. (2013). Inventar el futuro. Arte, Electricidad, Nuevos Medios. Nueva York: Departamento de Ficción.

Yeregui, M. (2013). Derivas y paisajes. En los confines del territorio.

(comp.) (2014). Prácticas de pensamiento en las artes electrónicas (y viceversa). Buenos Aires:

Autores de Argentina.

Recursos electrónicos

Bellonzi, M. \& Casacuberta, D. El Low Tech hispano. Recuperado el 12 de mayo de 2014. Disponible en: http://www.ub.edu/imarte/investigacions/estudis-teorics/david-casacuberta/el-lowtech-hispano Gianetti, C. (2002). La producción de contenidos culturales (2): arte, patrimonio, canales de difusión. Recuperado el 19 de mayo de 2014. Disponible en: http://www.uoc.edu/culturaxxi/esp/articles/giannetti0602/giannetti0602.html Mariátegui, J.C. \& Villacorta, J. Insular Areas of Media Creativity in Latin America. Initial findings on art, science and technology in groups and non-represented areas of Latin America. Recuperado el 12 de mayo de 2014. Disponible en: http://portal.unesco.org/.../Latin\%2BAmerica_Insular.doc

Abstract:

The electronic art category involves a large variety of practices located in the intersection of art, science and technology. While many contemporary argentinian artists are working in this field, the electronic art seems to be still restricted to an universe isolated from other present artistic expressions. This article poses a number of 
questions about the Latin American electronic art, specially in Argentina, and the possibility to trace through them an approach to the local cultural components. Next, the article approaches the strategies developed by some artists who have allowed to channel the artistic research without repeating mimetically alien and inherited technological imaginaries or ascribed to certain discursive lines as a legitimizing means of new proposals. As a conclusion the article analyzes the institutions devoted to the difusion to electronic art in Argentina and other Latin American countries. In addition, the paper stands on the importance of promoting initiatives to fund learning, exchange, production, exhibition and reflection on the electronic art of our country.

Key words:

electronic art - Latin America - contemporary argentinian art - low tech - creative local solutions.

Resumo:

A categoria de artes eletrônicas compreende uma pluralidade de práticas localizadas na interseção da arte, a ciência e a tecnologia. Enquanto vários artistas argentinos contemporâneos estão trabalhando neste campo, as artes eletrônicas parecem ainda ser confinadas a um universo isolado do resto das expressões artísticas atuais. Este artigo abre interrogantes ligados às particularidades das artes eletrônicas latino-americanas, em especial as argentinas, e à possibilidade de traçar através delas uma aproximação aos componentes culturais locais. Depois se desenvolvem as estratégias implementadas por alguns artistas que permitiram conduzir à pesquisa artística sem repetir mimeticamente imaginários tecnológicos estranhos e herdados, nem atribuir a determinadas linhas discursivas como meios de legitimação de novas propostas. O artigo conclui com a análise das instituições que estão avocadas à difusão das artes eletrônicas na Argentina e outros paises da América Latina. Também, destaca a importância de estimular iniciativas que financiem a aprendizagem, intercambio, produção, exibição e reflexão sobre as artes eletrônicas de nosso pais.

Palavras chave:

artes eletrônicas - América Latina - arte argentino contemporâneo - low tech - soluções criativas locais.

Artes electrónicas en Argentina. En busca del eslabón perdido fue publicado de la página 141 a página154 en Cuadernos del Centro de Estudios de Diseño y Comunicación № 60 